\title{
Direitos humanos e educação para uma outra democracia
}

Carlos V. Estêvão*

\section{Resumo}

Neste artigo, irei situar a questão dos direitos e da justiça numa outra forma de encarar a democracia, mais deliberativa e comunicativa. Nesse sentido, proporei a compreensão da "democracia como direitos humanos" explorando a especificidade e 0 alcance de dois dos seus vetores: a politicidade e a dialogicidade, num segundo momento, explicitarei as implicações desta concepção de democracia na educação, acentuando de modo particular as exigências de uma educação democrática, aberta aos desafios da participação e da cosmopoliticidade, assim como aos requisitos das diversas escalas de justiça.

Palavras-chave: Democracia. Justiça. Direitos humanos. Cosmopoliticidade. Educação.

\section{Human rights and education for another democracy Abstract}

In this paper I intend to place the issue of rights and justice in another way of understanding the democracy that is more deliberative and communicative. In this sense, I propose the understanding of democracy as human rights and I wonder the specificity and aim of politicity and dialogicity vectors that should characterize this type of democracy. I conclude this article by explaining the implications of this conception of democracy in education, stressing in particular the requirements of a democratic education, open to the challenges of participation and of cosmopoliticity, to the requirements of different scales of justice.

Keywords: Democracy. Justice. Human rights. Cosmopoliticity. Education

* Doutor em Educação; Professor Catedrático do Instituto de Educação Universidade do Minho, Braga, Portugal. E-mail: cestevao@ie.uminho.pt 


\section{Derechos humanos $y$ educación orientada hacia otra democracia Resumen}

En este artículo se plantea el tema de los derechos humanos y de la justicia, como una manera diferente de ver la democracia, más deliberativa y comunicativa. En este sentido, se propone la comprensión de la "democracia como derechos humanos", poder desarrollar la especificidad y el alcance de sus dos vectores: la politicidad y la dialogicidad. En segundo lugar, explicar las implicaciones de esta concepción de la democracia en la educación, hacer hincapié en las exigencias de una educación democrática, abierta a los desafíos de la participación y de la cosmopoliticidad, así como también a los requisitos de los distintos niveles de justicia.

Palabras clave: Democracia. Justicia. Derechos humanos. Cosmopoliticidad. Educación.

\section{Dos direitos e da justiça em nome de outra democracia}

Muitas críticas têm sido dirigidas aos direitos humanos ao longo dos tempos, provindas designadamente de várias concepções de mundo, de tradições culturais, de pressupostos filosóficos, de confissões religiosas.

Actualmente, uma das críticas recorrentes prende-se com a leitura dos direitos humanos enquanto expressão jurídica formal do homo oeconomicus, do indivíduo possessivo, servindo para legitimar e institucionalizar uma nova forma de poder político nem sempre muito compativel com as especificidades das vivências democráticas dos diversos povos.

Outros autores, porém, preferem acentuar a actual ditadura do relativismo (MATLARY, 2008), que acaba por contaminar os direitos, dando-lhes um cunho "multiuso" em termos de justificação. Neste sentido, e em oposição à virtude pública do homem clássico, o que importaria agora realçar seria 0 homem autorreferencial, que condicionaria não apenas as concepções de ética pública mas também a própria democracia. 0 homem, neste sentido, seria a medida de todas as coisas.

Em linha com este pensamento, o que de facto importaria agora, segundo a interpretação de Matlary (2008), seria uma concepção de direitos humanos em que a política emergiria fragmentada, carecendo de ideologia, vivendo uma situação que Nietzsche diagnosticou, há um século, no livro Para além do Bem e do Mal; na verdade, estariamos perante o relativismo que negaria o valor de qualquer norma comum exceto o do "politicamente correcto".

Ensaio: aval. pol. públ. Educ., Rio de Janeiro, v. 19, n. 70, p. 9-20, jan./mar. 2011 
Mas a relação entre direitos humanos e democracia, que aqui nos interessa, enfrenta outros desafios. Embora não os queira enumerar aqui, apenas queria destacar um deles tendo em conta a sua actualidade. Refiro-me à prevalência dos direitos do Estado sobre os direitos dos indivíduos, detendo aquele um poder quase absoluto sobre os cidadãos que vivem dentro do seu território. Na verdade, as fronteiras do Estado delimitariam as fronteiras dos direitos e da justiça, permanecendo deste modo o discurso normativo ortodoxo dos direitos humanos largamente assente na linguagem de uma sociedade internacional de Estados. Diz Stammers $(2009$, p. 115) a este propósito que a consequência da institucionalização dos direitos humanos nos Estados-nação modernos tem resultado em compreensões, abordagens e políticas relativamente aos direitos humanos que são muitas vezes profundamente ambíguas em relação ao poder; acabando este facto por ter implicações negativas na imagem dos próprios direitos.

Não é, por isso, surpreendente que muitos dos pensadores atuais, posicionados na urgência de repensar a justiça, nos estejam a propor que as democracias atuais necessitam de se renovar, desde logo pelo reconhecimento de diferentes escalas de justiça e pelo respeito das diferentes identidades cosmopolitas que "compõem" o cidadão, o que aponta para uma concepção também mais rica e densa de democracia (como é o caso daquela que venho propondo, baseada nos direitos humanos, que desenvolverei mais à frente).

Com esta renovação, recoloca-se num patamar superior quer a democracia quer os direitos, quer mesmo a própria construção da "paz perpétua", deixandose, por conseguinte, de vincular estes conceitos de uma forma redutora à soberania estatal ou às narrativas nacionais as quais, segundo Wieviorka (2002, p. 202), se apoiam frequentemente num "episódio fundador particularmente bárbaro", ao mesmo tempo que recusam a mestiçagem e a mistura por supostamente mancharem a imagem da raça pura, normalmente branca.

Face a todos estes desafios, há então que encontrar um sentido mais profundo de democracia, que substancialize e, actualize os direitos humanos face aos fenômenos contemporâneos, indo para além das definições clássicas que a remetem de uma forma muito linear para a categoria da igualdade e para outras categorias políticas modernas como as de autoridade, de representação e de soberania. De facto, hoje há outros embates que têm a ver mais com a centralidade da diferença (gênero, idade, étnica...), com outras escalas de justiça (desde a local à global), com outros objetos que passaram a ser assunto de decisão do poder político e que tradicionalmente se situavam no espaço privado (como os relacionados com a biopolítica ou a política da vida).

Com o propósito de encontrar um novo conceito de democracia, Goodhart (2005) propõe uma democracia emancipatória, realizada através dos direitos humanos. Aqui, a universalidade dos direitos emerge como global e diz respeito a todas as pessoas humanas 
como sujeitos políticos, exigindo-se, ainda, a responsabilização de todos na democratização interna de cada Estado, porque os ideais de maior liberdade e igualdade para todos continuam válidos e significativos. Dai que, no seu enquadramento normativo, Goodhart $(2005$, p. 135) defina democracia "como direitos humanos", entendida como "compromisso político com a emancipação universal através do assegurar a todos igual fruição dos direitos humanos fundamentais". Consequentemente, o sentido da democratização altera-se: não visa já criar instituições representativas majoritárias mas antes "criar garantias institucionais seguras para os direitos humanos" (GOODHART, p. 150); que englobe as lutas históricas pela emancipação e inclusão mas também os atuais projectos de construção de uma democracia global, assim como o compromisso dos governos e da governança mundial com a garantia institucional dos direitos fundamentais (relacionados com a liberdade e a segurança, com a equidade/justiça, com um justo padrão de vida, com os direitos civis e políticos).

0 sentido, pois, mais profundo da democracia como direitos humanos prendese com a emancipação, que, por sua vez, se articula com a eliminação das estruturas de opressão e de exclusão, ou ainda, acrescento eu servindo-me das palavras de Booth (1999, p. 46), com "a teoria e a prática de inventar humanidade".

Uma das implicações então deste novo enquadramento dos direitos e da democracia é que eles sejam reinterrogados e reequacionados face às novas exigências em termos nomeadamente da compreensão da justiça. Já não basta a justiça socioeconômica ou redistributiva, nem mesmo a justiça cultural-simbólica ou de reconhecimento, ambas confinadas na sua validade aos limites do Estado; agora também importa a justiça como representação política ou participação. Dai que as preocupações de Fraser (2009), por exemplo, em reconstruir as fundações meta-políticas da justiça no mundo globalizado, invocando o princípio pós-westfaliano para ultrapassar a lógica territorialista dos Estados, sejam perfeitamente compreensiveis.

Consequentemente, a noção de justiça democrática pós-wesfaliana ganha centralidade, afirmando como uma das injustiças do tempo actual a não-representação metapolitica, a qual acontece quando os Estados e as elites transnacionais monopolizam o poder, bloqueando a criação de fora democráticos, excluindo da participação outros povos ou grupos através de meta-discursos que determinam a divisão autoritária do espaço político. Ora, as lutas pela justiça num mundo globalizado não podem ter sucesso a não ser que venham de mãos dadas com as lutas pela democracia meta-política, sendo esta precisamente uma das dimensões da democracia como direitos humanos.

Independentemente de outros desenvolvimentos e de outras caracteristicas que eu poderia ressaltar nesta concepção de democracia, como direitos humanos, sinalizaria duas que subjazem ao nosso relacionamento social, à interlocução, à convivência, ao fazer público, à própria ética; refiro-me à cosmopoliticidade e à dialogicidade, tão caras a vários autores, com destaque para Paulo Freire.

Ensaio: aval. pol. públ. Educ., Rio de Janeiro, v. 19, n. 70, p. 9-20, jan./mar. 2011 
Na sequência de trabalhos anteriores em que o tema foi aprofundado (ESTÊVÃO, 2005, 2009a), a cosmopoliticidade (e não cosmopolitismo!) permite não apenas chamar a atenção para a responsabilidade global mas também para a necessidade de aplicar os princípios da democracia à escala mundial, ampliando explicitamente a dimensão da politicidade Freiriana - expressa nas obras Educação como Prática de Liberdade (FREIRE, 1975) e A Educação na Cidade (1991) por exemplo - a esse mesmo nivel global. Assim concebida, considero que a politicidade pode ser traduzida na cosmopoliticidade ao serviço da cidadania terrestre e assente em valores fundamentais como, por exemplo, os direitos humanos. Esta compreensão articulase também com a ética da justiça universal, mas contextualizada, de Freire, quando nos diz no livro Pedagogia da Indignação (2000, p. 129):

faz tão parte do domínio da ética universal do ser humano a luta em favor dos famintos e destroçados nordestinos, vítimas não só das secas, mas, sobretudo, da malvadez, da gulodice, da insensatez dos poderosos, quanto a briga em favor dos direitos humanos, onde quer que ela se trave. Do direito de ir e vir, do direito de comer, de vestir, de dizer a palavra, de amar, de escolher, de estudar, de trabalhar. Do direito de crer e de não crer, do direito à segurança e à paz.

Trata-se, por conseguinte de uma militância a favor do "sonho ético-político da superação da realidade injusta" (FREIRE, 2000, p. 43), de modo a que se produza uma mudança do status quo, no sentido de fazer do mundo um mundo menos feio, mais humano, mais justo e mais decente.

Esta preocupação pela instauração de uma ética universal transparece também nas preocupações em denunciar, na obra Pedagogia do Oprimido (2005a), a malvadez intrínseca e o caráter necrófilo das elites dominadoras que se fecundam no esmagamento dos oprimidos e thes propõem a admiração de um falso mundo.

Ou seja, a cosmopoliticidade, na continuidade, insisto, do conceito Freiriano de politicidade, reporta-se a uma dimensão essencial do pensamento de libertação, da orientação educacional e de indignação perante as injustiças e a pobreza.

No que concerne à vertente da dialogicidade ou da dialogação, Freire, nos seus livros Pedagogia do Oprimido (2005a) e Cartas a Cristina (1996), realça de uma forma inequívoca a riqueza intrínseca deste conceito, articulando-o intimamente com o amor profundo pelas pessoas e pelo mundo, uma vez que é precisamente este amor a base do diálogo e o próprio diálogo, sem dominação e fiel à sua causa de libertação (FREIRE, $1975,2005 b)$. Consequentemente, a dialogicidade em Freire está na base da sua concepção antropológica, ao serviço ou como condição primordial da libertação dos oprimidos, da humanização ("ser mais") do homem, da construção de um mundo mais 
humano e com sentido: "Existir humanamente é pronunciar o mundo, é modificá-lo. 0 mundo pronunciado, por sua vez, se volta problematizada aos sujeitos pronunciantes, a exigir deles novo pronunciar" (FREIRE, 2005a, p. 78, grifos do autor).

Para finalizar este ponto, uma democracia como direitos humanos, como emancipação construída na cordialidade (SANTOS, 2004), é uma proposta que não abdica da universalidade dos direitos, mas que claramente the traça um percurso, construida, como vimos, na interdialogação, na dialecticidade, aceitando o caráter conflitual ou político da vida social e recusando, por isso mesmo, os lugares marcados ou a ordem universal actualmente existente em nome da parte que, embora inerente a essa mesma ordem universal, não tem um justo lugar no seu interior (como, por exemplo, os "sem papéis" ou os "sem abrigo"), excluída pela própria ideia de universalidade (ZIZECK 2006, p. 65).

\section{Da educação democrática e cosmopolítica}

0 direito à educação foi uma bandeira do século passado desfraldada em nome dos ideais modernizadores e desenvolvimentistas e fundamentado nos princípios da llustração Se, por um lado, aqueles ideais eram libertadores por combaterem a ignorância, por outro lado, intentavam socializar a população dentro de um dado sistema hegemônico e, por isso, com uma intencionalidade reprodutora da ordem social vigente.

Ora, o direito à educação é um direito que requer muitas batalhas em várias frentes, sendo algumas lutas no campo do discurso, que implicam tomada de posição, luta de sentidos de dominação e de resistência, enfim, lutas de poder. Isto equivale a defender que a educação é um direito humano e social inalienável que requer a recuperação da política nas discussões sobre os assuntos públicos. Com efeito, os sentidos que atribuímos às nossas ações, a expressão que damos às nossas necessidades, as interpretações que fazemos de como as coisas são, não deixam de ser arenas de lutas políticas e, por isso, a educação deve estar desperta para esta realidade.

Em outras palavras, a politicidade da educação deve emergir de forma clara, apesar da espuma da lógica economicista que rege as atuais políticas neoliberais que tende a ocultála e a considerá-la até digna de ser arrumada no sótão da história. Esta assunção pela educação da sua politicidade exige desde logo que ela reconheça os debates educativos quer como política pública, dizendo respeito a todos e em que todos devem participar, quer como política de Estado. Ou seja, e seguindo Freire, a educação não é nem pode ser neutra, pois ela "tanto pode estar ao serviço da decisão da transformação do mundo, da inserção crítica nele, quanto ao serviço da imobilização, da permanência possivel das estruturas injustas, da comodação dos seres humanos à realidade tida como intocável" (FREIRE, 2000, p. 58). Por outro lado, diz-nos no livro A importância do ato de ler (FREIRE, 1997, p. 76), a educação crítica, integrada no processo de libertação, deve ajudar educadores e estudantes, através da desmitificação da realidade, a ultrapassarem a iletracia política, permitindo-lhes posicionar-se de modo mais consistente na dialogação pública.

Ensaio: aval. pol. públ. Educ., Rio de Janeiro, v. 19, n. 70, p. 9-20, jan./mar. 2011 
De facto, numa democracia com direitos humanos, profundamente comunicativa e sem fronteiras, também a educação tem o seu lugar bem demarcado: ela deverá alcandorar-se ao patamar de uma educação cosmopolítica, contribuindo para transcender as condições de dominação e opressão, de exploração, de marginalização e não-reconhecimento, de não-participação e desrespeito, evitando o que Arendt designou por "morte política" e possibilitando às instituições educativas que elas próprias gerem, entre outras coisas, "poder social para" e não "poder social sobre" (STAMMERS, 2009).

0 projecto emancipatório, para o qual uma educação para os direitos humanos deve contribuir divulgando-o como teoria e como projecto prático de humanização, pressupõe e reivindica a capacidade de intervir efetivamente para realizar a transformação social positiva, através da mediação da dialógica política, através do debate democrático, com a plena paridade de participação, não obstante os obstáculos que se erguem e que têm a ver, por exemplo: com a falta de acesso aos recursos econômicos e sociais; com o estigma social e os estereótipos associados à pobreza; com formas de não reconhecimento de injustiças ligadas ao gênero, à orientação sexual, às incapacidades, entre outras; enfim, com a remissão para 0 interdito que impede os dominados de aparecerem no espaço público a não ser de maneira ridícula ou alienada e, em todo o caso, subjugada (WIEVIORKA, 2002, p. 155). Ou seja, reconhecendo que é mais fácil para os que dispõem de recursos econômicos e políticos participarem enquanto identidades abastadas, na coisa pública, tal não pode implicar a sonegação da possibilidade de uma participação política substantiva a todos os cidadãos, devendo, para tal, a educação contribuir para a simetrização das relações sociais, culturais e políticas.

Na verdade, se, como diz Fraser (2007), a norma de paridade de participação deve ser aplicada dialógica e discursivamente, através de processos democráticos de debate publico, e se, ao mesmo tempo, a deliberação democrática justa concernente aos méritos da redistribuição e das exigências de reconhecimento exige paridade de participação para todos os deliberadores atuais ou potenciais, impõe-se, desde logo, que a educação de alcance cosmopolítico propicie e facilite este posicionamento democrático (LOVELL, 2007), denunciando situações de desigualdade e inaugurando outras condições de acesso à "voz".

Será, pois, desta cosmopoliticidade democrática (ESTÊVÃO, 2007) que a educação deve extrair o seu programa, não apenas pela reteorização das relações entre escola pública e democracia (esta apontando, no actual contexto, para a possibilidade de cada cidadão poder gozar de cidadanias múltiplas, tendo em conta os contextos que o afetam) mas também, e de uma forma mais concreta, pelo modo como se estrutura e organiza a própria escola, concebendo-a como "lugar de vários mundos" (ESTÊVÃO, 2004), como lugar de uma poliarquia de principios de justiça que requerem novas argumentações a favor da civilidade democrática e crítica. 
Do mesmo modo, a aprendizagem deve, neste enquadramento, ser encarada como um processo de compromisso com o "outro", com a razão e os direitos humanos, numa distribuição igual das oportunidades e perspectivas de vida (OLSSEN, 2004). Com efeito, a aprendizagem deve entender-se, na linha de pensamento deste autor, como um compromisso político e social numa comunidade global, constituindo, deste modo, uma forma de participação política e democrática, que deve atender à igualdade, ao papel do Estado para garantir o acesso à educação, ao conhecimento e à informação, ao desenvolvimento da sociedade civil. Por outras palavras, a aprendizagem transformadora aqui delineada, tendo em vista o exercício do "direito a ser mais" (FREIRE, p. 2005a), implica processos de tomada de decisão participados, a oposição à colonização tecnocrática da mesma aprendizagem, tendo como meta a promoção do conhecimento mútuo e a auto-compreensão coletiva. A aprendizagem institui-se, assim, como um meio de promoção de mudanças locais para influenciar o global no sentido de construir cidadania através de estratégias e de métodos participativos, dando vez e voz a todos, incluindo aos marginalizados.

A educação cosmopolítica deve, de facto, posicionar-se de modo a potenciar novos direitos, como o da solidariedade, contrariando o movimento da educação em torno do self mais individualizado, ou da educação baseada na criação do "cosmopolita estratégico", do cidadão como jogador econômico globalmente orientado (MITCHELL, 2003); ela deve, pelo contrário, investir na promoção do "self cosmopolita" participativo, integrado em redes de solidariedades locais e transnacionais de cooperação, mas também de oposição. E aqui destacaria de modo particular a sensibilidade que é urgente desenvolver pela educação ao flagelo da pobreza, com a sua vertente da fome, perante a qual Gentili (2010) se questiona muito pertinentemente se é possivel alguém dedicar-se à educação sem compreender como funciona a fome; ou seja, como é possivel dizer-se que se defende a escola pública e as políticas educativas democráticas quando a fome não se impõe, por exemplo, como um problema analítico relevante nas nossas escolas de formação de professores e nas nossas universidades?

Em suma, considero que a educação cosmopolítica tem a vantagem de saber lidar com as diferentes racionalidades, destacando a racionalidade cosmopolítica que densifica as possibilidades de a Humanidade encontrar respostas concretas e adequadas para os seus problemas (SANTOS, 2002), partindo ao mesmo tempo da ideia de que todas as culturas são incompletas e que podem, por isso, ser enriquecidas pelo diálogo e pelo confronto com outras culturas.

Com efeito, a educação cosmopolítica deve apoiar a construção do acordo cada vez mais amplo e entrecruzado entre distintos lugares, pela conversação ou interdialogação (APPIAH, 2004; SANTOS, 2004), construindo-se uma universalidade ética concreta, de confluência, que "vem de baixo", cordial e sensivel às necessidades das vitimas dos projectos totalizadores. Trata-se, enfim, de uma educação que se apre- 
senta com tensões, com dilemas, com diferentes percepções das questões globais, mas que não perde o norte relativamente à preocupação de contribuir para um mundo com maior justiça, equidade e direitos humanos para todos, mantendo, por isso, uma estreita ligação com a educação para o desenvolvimento, com a educação para os direitos humanos (ESTÊVÃO, 2009b), com a educação intercultural e com a educação para a paz. É que a educação cosmopolítica tem a ver não apenas com o que se ensina e aprende, mas sobretudo com o modo como se ensina e aprende, com as atitudes e valores, tendo em vista a transformação social (o "anúncio") e tendo presente que cada vez mais os problemas e questões devem ser colocados em vários niveis para uma maior compreensão não apenas dos temas globalizados mas dos problemas mais próximos de nosso dia-a-dia, do nosso micro-contexto.

Penso, para terminar este ponto, que é a educação cosmopolítica que melhor contribuirá para reconfigurar verdadeiramente a noção de público como uma "forma de solidariedade social" (CALHOUN, 2002, p. 159), propiciando também uma maior abrangência e inclusividade dessa esfera pública, na medida em que aponta, em sintonia com a democracia como direitos humanos, para a urgência da sua compreensão como esfera pública global.

Consequentemente, estamos perante uma educação de amorização, que, num mundo globalizado, deve "conservar e transmitir o amor intelectual ao humano" (FREIRE, 2000, p. 124), amor que é universal, que tem como condição o respeito pelos direitos humanos, devendo integrar-se num projecto mais profundo de um mundo como uma "comunidade de comunidades", regida por uma ética cosmopolítica, radicalmente embebida em pressupostos de paz, de convivência democrática, de cidadania cosmopolítica.

Face a estes pressupostos, considero que a educação cosmopolitica numa democracia como direitos humanos se inscreve claramente no impeto de uma educação emancipatória e dialógica, baseada numa mundividência de humanismo crítico.

\section{Conclusão}

Face a uma maior interdependência econômica, política e cultural; a uma maior expansão da democracia e de reivindicações de paz; ao crescimento de uma maior consciência dos problemas humanitários e ambientais ao nível global; ao processo que tem levado os indivíduos a reconstruírem mais lealdades complexas e identidades de múltiplos níveis; aos movimentos crescentes de bens culturais através das fronteiras; à hibridação e à mistura de culturas; à reprogramação da própria comunidade política, pelo caudal de fluxos regionais, internacionais e globais de recursos e de redes de interação, não parece insensato se pensar que caminhamos, efetivamente, para uma espécie de comunidade cosmopolita ou "sem fronteiras", que deve assentar numa nova base e em novos processos de praticar a democracia, os direitos e a justiça social.

Ensaio: aval. pol. públ. Educ., Rio de Janeiro, v. 19, n. 70, p. 9-20, jan./mar. 2011 
Não desconhecendo que esta abertura planetária pode ser potenciadora de perigos, a minha opção neste trabalho orienta-se para a defesa de uma globalização contra-hegemônica, com a sua virtude cosmopolitica, que requer novas formas de atuar por vias emergentes de solidariedade, novas formas de pensar, de conhecer, de amar e de ser no mundo, tendo sempre presente, como valores centrais, a justiça social global, a democracia comunicativa e como direitos humanos, a solidariedade transnacional.

Esta é uma forma mais radical de conceber as pertenças dos cidadãos, alocandoas em comunidades entrecruzadas, comprometidas com a equalização social e econômica, com a responsabilidade de resistir e de politizar a vida social, de contribuir para o desenvolvimento de estruturas políticas mais participativas e solidárias.

Penso que, deste modo, a democracia ganhará um novo fôlego, deixando de se confinar à territorialidade estatal para se abrir ao espaço público global nas suas dimensões políticas, culturais e cívicas, valorizando ao mesmo tempo um novo entendimento entre todos, construído na dialogação cordial, sem coações, ampliando e consolidando fora comunicativos, capazes de gerar normas democráticas a partir dos direitos humanos.

Para ser coerente, a educação deverá seguir este impulso, contribuindo para ver o Outro, esteja ele onde estiver, como um ser humano com quem devemos colaborar, que nos ajuda a crescer e que nos dá a alegria de o ajudarmos. Trata-se de uma educação cosmopolítica, ao serviço da sensibilidade em relação ao outro, investindo na solidariedade e na celebração da amizade, na fidelidade, mas também, e nas palavras de Freire (2000), na "rigorosidade ética", no "amar o mundo", lutando contra a passividade e contra os lugares marcados do Outro. Trata-se, enfim, de uma educação criativa, exigente e rigorosa, interessando-se por todos, mesmo por aqueles que não se interessam por ela.

E termino em tom Freiriano: a forma mais adequada e efetiva de conduzir 0 projecto de educação é a democrática, pois é ela que dá a oportunidade a todos de "estarmos presentes na História" como protagonistas e interlocutores e não como meros ouvintes ou como simples representados, contribuindo deste modo para a construção do projecto da democracia como direitos humanos. 


\section{Referências}

APPIAH K. A. Ciudadanos del mundo. In: GIBNEY, M. J. (Ed.). La globalización de los derechos humanos. Barcelona: Crítica, 2004.

BOOTH, K. Three tyrannies. In: DUNNE, T.; WHEELER, N. J. (Ed.). Human rigths in global politics. Cambridge: Cambridge University Press, 1999.

CALHOUN, C. Imagining solidarity: cosmopolitanism, constitutional patriotism and the public sphere, Public Culture, New York, v. 14, n. 1, p. 147-171, 2002.

ESTÊVÂO, C. V. Cosmopoliticidade e educação de adultos na era da globalização. Educação em Revista, Marília, SP, v. 10, n. 1, 2009a.

Direitos humanos, justiça e educação. Educação, Sociedade \&t Culturas, Porto, n. 25, p. 43-81, 2007.

Educação, justiça e democracia. S. Paulo : Cortez Editora, 2004.

. Educação para os direitos humanos em Portugal: uma breve radiografia. In: MAGENDZO, A. K. (Ed.). Pensamiento e ideas-fuerza de la educación en derechos humanos en Iberoamérica. Santiago do Chile: Ediciones SM, 2009b.

. Multiculturalidade, cosmopoliticidade e eticidade numa educação democrática. V Colóquio Internacional de Paulo Freire - Paulo Freire. Desafios à Sociedade Multicultural, realizado em 19-22 de Setembro de 2005, em Recife, Brasil, 2005.

FRASER, N. Re-framing justice in a globalizing world. In: LOVELL, T. (Mis)recognition, social inequality and social justice: Nancy Fraser and Pierre Bourdieu. New York, NY: Routledge, 2007.

Scales of justice: reimagining political space in a globalizing world. Cambridge: Polity, 2009.

FREIRE, P. Cartas a Cristina: reflexões sobre minha vida e minha práxis. São Paulo: Ed. da UNESP, 1996. Educação como prática de liberdade. 5. ed. Rio de Janeiro: Paz e Terra, 1975. Educação e mudança. 28. ed. São Paulo: Paz e Terra, $2005 b$. A educação na cidade. S. Paulo: Cortez, 1991. 
FREIRE, P. A importância do ato de ler e o processo de libertação. São Paulo: Cortez: Autores Associados, 1997.

Pedagogia da indignação: cartas pedagógica e outros escritos. São

Paulo: Ed. da UNESP, 2000.

Pedagogia do oprimido. 42. ed. Rio de Janeiro: Paz e Terra, 2005a.

GENTILI, P. Adoquines y anclas: el hambre de saber y los saberes del hambre. Revista Iberoamericana de Educación, [S. I.], n. 52/3, p. 4-14, 2010.

GOODHART, M. Democracy as human rights: freedom and equality in the age of globalization. New York: Routledge, 2005.

LOVELL, T. (Mis)recognition, social inequality and social justice: Nancy Fraser and Pierre Bourdieu. New York: Routledge, 2007.

MATLARY, J. H. Derechos humanos depredados: hacia una dictadura del relativismo. Madrid: Ediciones Cristiandad, 2008.

MITCHELL, C. Educating the national citizen in neoliberal times: from the multicultural self to the strategic cosmopolitan. Transactions of the Institute of British Geographers, Hoboken, NJ, v. 28, n. 4, p. 387-403, 2003.

OLSSEN, M. Neoliberalism, globalisation, democracy: challenges for education. Globalisation, Societies and Education, Surrey, UK, v. 2, n. 2, p. 231-275, July 2004. Disponivel em: <http://www.informaworld.com/smpp/ section?content=a713620757\&fulltext=7132409 . Acesso em: 8 out. 2008.

SANTOS, B. S. Para uma sociologia das ausências e uma sociologia das emergências. Revista Crítica de Ciências Sociais, Coimbra, n. 63, p. 237-280, 2002.

Do pós-moderno ao pós-colonial: e para além de um e outro: In: CONGRESSO LUSO-AFRO-BRASILEIRO DE CIÊNCIAS SOCIAIS, 7., Coimbra, 2004. Conferência de abertura... Coimbra, 2004.

STAMMERS, N. Human rights and social movements. London: Pluto Press, 2009.

WIEVIORKA, M. A diferença. Lisboa: Fenda Edições, 2002.

ZIZECK, S. Elogio da intolerância. Lisboa: Relógio d'Água, 2006.

Recebido em: 29/09/2010

Aceito para publicação em: 15/10/2010

Ensaio: aval. pol. públ. Educ., Rio de Janeiro, v. 19, n. 70, p. 9-20, jan./mar. 2011 